\title{
Chicago Ophthalmological and Otological society
}

\section{The Journal of the Amer. med. Association. June 17. 1899. May 9. 1899}

Blood exudate in cornea. Hotz stellte einen Patienten vor, der eine sehr seltene Affektion seines linken Auges zeigte. Es war ohne jede nachweisbare Ursache und ohne Schmerzen eine das Centrum der Hornhaut einnehmende, an Grösse allmählich zunehmende, scheibenförmige, rot gefärbte Trübung aufgetreten, die zweifellos ein blutiges Exsudat darstellte. Im übrigen war das Auge in normalem Zustande, aueh die vordere Kammer voll-kommen frei und klar. Hotz ist der Meinung, dass es sich ursprüng-

216

-Sitzungsberichte.

licb um einen spontanen Bluterguss in die vordere Rammer gehandelt haben und von dort durch Diffusion Blutfarbstoff in die Cornea ein-gedrungen sein miisse, da doch von einem direkten Bluterguss in das Gewebe aus anatomischen Gründen keine Rede sein könne. Mit dieser Auffassung stimmen auch frübere Beobachtungen überein, bei denen die microscopische Untersuchung niemals korpuskuläre Elemente des Blutes, sondern nur Ilämatoidin-Rrystalle ergeben babe. Unerklärt bliebe nur das ganz spontane Auftreten der Blutung.

Ophthalmolog $\cdot$ ical society of the united Kingdom.

June 9. 1899. (The operative treatment of myopia.)

Eine Discussion über diesen Gegenstand wurde von R. Cross er-öffnet, der nach einem geschichtlichen Ueberblick und der Angabe der Operations-Technik seine Erfahrungen über 48 operierte Fälle mitteilt, die alle ein gutes Resultat gaben. “Wenigstens „,hatte der Vortragende die Operation in keinem Falle zu bereuen-'. Es wurde stets nur ein-seitig operiert und in der Regel nur Fälle über 15 D. M. In einem Falle nur wurde bei 7 D. M., aber von deutlich progressivem Character, die Operation vorgenommen. Deutliche Glaskörpererkrankungen, Neigung zu intraoculären Blvtungen und $\lambda$ Yeichheit des Bulbus galten als Contraindication für die Operation.

Lang berichtet über 30 17/8lle; in 1 Falle trat Ablatio ret. ein; aber dasselbe geschah auch auf dem nicht operierten 2. Auge.

Treacher berichtet über 11, Cargill über 6, Frost über 24, Batten über 13 operierte Augen. (The British med. Journ. June 17. 1899. p. 1467.)

1. Beevor und Gunn, A case of obliteration of a branchof the retinal artery following frequent attacks of temporaryamblyopia.

Beevor und Gunn berichten von einem 34jährigen Manne, der seit seiner Rindheit an vorübergehenden, einige Minuten andauernden Anfällen von Amblyopie gelitten hatte, die vorwiegend das rechte Auge betrafen und ohne Ropfschmerzen einhergingen. Vor 9 Monaten blieb nach einem solchen Anfall der Verlust der oberen Gesichtsfeld-hälfte des rechten Auges zurück; er blieb bestehen und fand in einer Atrophie der unteren Papillenhälfte und in einer Obliteration der Zweige der unteren Hälfte der Art. centr. ret. seinen anatomisclien Aus-druck. Gelegentlich trat auch einmal ein vorübergehender Verlust der-unteren Gesichtsfeldhälfte des linken Auges ein. 
2. . Recovery of sight after partial occlusion of thecentral artery.

Story berichtet iiber 2 Fälle von typischer Embolie der Central-arterie mit Wiederherstellung des Sehvermögens

das im 1. auf Licht- 